\title{
Introdução à pesquisa em um curso de graduação: sobre bibliotecas populares e formação de leitores
}

\section{The introduction to research in a graduation course: about popular libraries and readers' development}

\author{
Márcia Cabral da SILVA
}

\begin{abstract}
RESUMO
Neste trabalho busca-se apresentar alguns resultados da pesquisa desenvolvida nos períodos iniciais em turma de graduação em uma universidade pública no contexto do Estado do Rio de Janeiro, cujo tema refere-se a bibliotecas populares e à formação de leitores. Na primeira fase retratada neste trabalho, levantaram-se o histórico e o modo de funcionamento atual de bibliotecas populares situadas na Cidade do Rio de Janeiro, de modo a construir atitude investigativa por parte de vinte de oito alunos, distribuídos em oito bibliotecas populares nos diversos bairros da cidade. Além dos referenciais teórico-metodológicos relacionados aos conceitos de biblioteca, de leitura e de história da leitura, foram introduzidas as primeiras noções relacionadas à pesquisa de natureza etnográfica e à investigação na esfera das Ciências Humanas.
\end{abstract}

Palavras-chave: pesquisa, graduação, bibliotecas populares, formação de leitores.

\begin{abstract}
The present study shows some results of a research developed in the first degrees in a graduation course in a public university within Rio de Janeiro State. It is related to public libraries and readers' development. In the first stage, carried out in this study, we investigated the history and the monitoring of public libraries within Rio de Janeiro City, so that we could stimulate the researching attitude by twenty eight students involved in it, which we distributed among eight libraries all over the city. Besides the theoretical and methodological references related to the concepts of library, reading and the history of reading, we introduced the first notions concerned the ethnographic research and the investigation in the field of Human Sciences.
\end{abstract}


Index Terms: research, graduation, public libraries, development of readers.

\section{Introdução}

Este trabalho visa apresentar algumas reflexões teóricas e metodológicas acerca da construção de uma pesquisa sobre a rede de bibliotecas populares na Cidade do Rio de Janeiro e a formação de leitores, realizada junto a um grupo de alunos de graduação, cursando, em sua maioria, o $2^{\circ}$ período na Faculdade de Educação, de uma universidade pública localizada no Estado do Rio de Janeiro. ${ }^{1}$

Os estudos recentes sobre níveis de letramento e formação de leitores, em especial, entre os jovens e a população adulta, têm apontado dados que influenciam consideravelmente os indicadores sociais de qualidade de vida. Por um lado, conforme o censo 2000 do IBGE, no Brasil, há 17,6 milhões de pessoas com 10 anos ou mais que não sabem ler ou escrever. Em 2002, registravam-se 14,6 milhões de analfabetos (11,8\% da população de 15 anos ou mais de idade) e o país tinha 32,1 milhões de analfabetos funcionais. (IBGE, PNAD, 2002). Por outro lado, com relação aos estudantes que freqüentam a escola, os prognósticos são pouco promissores. Resultados de pesquisa divulgados pelo INEP/MEC, em abril de 2003, aparecem veiculados em matéria com o seguinte conteúdo "nível de leitura e matemática da maioria dos alunos é crítico. A maioria dos estudantes não aprende a ser leitor para realizar atividades básicas do

\footnotetext{
${ }^{1}$ Trata-se do componente curricular Pesquisa e Prática Pedagógica, com duração de seis períodos letivos, cujo objetivo é congregar os alunos, a partir do primeiro período do curso de Pedagogia, em um grupo de pesquisa que desenvolva temática de seu interesse. No $2^{\circ}$ semestre de 2005, etapa retratada neste trabalho, fizeram parte desta pesquisa 28 alunos, distribuídos em 8 bibliotecas populares na cidade do Rio de Janeiro (Biblioteca Popular da Penha - Álvaro Moreira, Biblioteca Popular de Irajá - João do Rio, Biblioteca Popular de Bangu -Cruz e Souza, Biblioteca Popular do Engenho Novo - Agripino Grieco, Biblioteca Popular da Tijuca - Marques Rebelo, Biblioteca Popular de Santa Teresa - José de Alencar, Biblioteca Popular de Botafogo - Machado de Assis e Biblioteca Popular do Grajaú Clarice Lispector).
} 
cotidiano, inserir-se na complexa sociedade globalizada e exercer plenamente a cidadania. Esta é a conclusão de estudo sobre a quarta série do ensino fundamental".

Além dos dados extraídos dessas pesquisas, os resultados de Ribeiro (2003) referentes ao Indicador Nacional de Alfabetismo Funcional (INAF) revelam que habilidades básicas de leitura e de escrita estão distribuídas de forma desigual entre a população brasileira. Acresça-se que a pesquisa Retrato da Leitura no Brasil (CBL, 2001) aponta questões interessantes sobre leitura, como, por exemplo, o fato de que grande parte dos brasileiros gosta de ler livros. Por que se afirma, então, que brasileiro não lê, que as formas de acesso ao livro são bem restritas em nosso país?

Acreditamos que este quadro não possa ser analisado de forma isolada, uma vez que, no Brasil, relaciona-se com altos índices de exclusão social: renda, saúde, alimentação e acesso aos bens culturais produzidos coletivamente, mas ainda usufruídos por poucos. Verificamos, portanto, a necessidade de um estudo específico sobre as redes de acesso à democratização da leitura que possa fundamentar diagnósticos de políticas públicas e sociais para questão relevante como a apropriação da leitura em nosso país.

\section{Metodologia e quadro teórico de pesquisa: algumas considerações}

$\mathrm{Na}$ perspectiva acima destacada, tivemos como objetivo inicial investigar a rede de bibliotecas populares da Cidade do Rio de Janeiro, situadas nos mais diversos bairros: Bangu, Ramos, Botafogo, Irajá, dentre outras, totalizando à época vinte e seis unidades, sendo a mais recente a 
Biblioteca Popular do Complexo da Maré, inaugurada em maio de $2005^{2}$. Esta rede faz parte da Secretaria Municipal das Culturas e integra o Departamento Geral de Documentação e Informação Cultural.

A pesquisa de uma área das Ciências Humanas - a Educação requer escutar, ouvir, observar, considerando tanto a racionalidade quanto a sensibilidade, a fim de não perdermos de vista a história e a experiência dos sujeitos envolvidos. Desse modo, a pesquisa qualitativa constitui-se na abordagem que melhor possibilita compreender os sujeitos que fazem parte da investigação, sem emudecê-los, neutralizá-los.

Para o desenvolvimento da pesquisa etnográfica, planejamos estratégias metodológicas complementares: entrevistas sem-estruturadas individuais e coletivas - com o intuito de melhor captar as falas dos atores sociais envolvidos, em um ambiente que possibilitasse a narração e a troca de experiências, além da observação cuidadosa do campo, procurando conhecer os contextos de vida, as formas de pensar e de se comportar dos pesquisadores e dos grupos sociais estudados (cf. FERREIRA e AMADO, 2002; MINAYO, 1992, 2003 e OLIVEIRA, 1998.).

Tendo em vista a natureza da pesquisa, optamos pela distribuição dos pesquisadores nas bibliotecas, em pequenos grupos, utilizando o critério de proximidade do local de residência ou de fácil acesso, em função do local de trabalho. De tal modo, tivemos que modificar o seu objetivo inicial, adotando um modo de investigação que contemplasse o estudo de vinte e oito pesquisadores, distribuídos em oito bibliotecas. Esta foi a sistematização exeqüível para conduzir a pesquisa na primeira etapa, cujo enfoque privilegiou o levantamento do histórico dessas instituições e o modo de funcionamento atual.

Algumas perguntas nortearam a escolha do quadro teóricometodológico do estudo sobre a história das bibliotecas pesquisadas: o que é

\footnotetext{
${ }^{2}$ Dados colhidos junto à Secretaria Municipal de Culturas da Cidade do Rio de Janeiro em julho de 2005 .
} 
biblioteca pública/ popular? De que modo as bibliotecas populares na Cidade do Rio de Janeiro surgiram? Como relacionar os dados históricos com o modo de funcionamento atual?

Para Milanesi (1983), autor que nos acompanhou em grande parte na investigação inicial, biblioteca pública deveria apresentar um determinado perfil:

(...) cada biblioteca serve a um determinado público. Quanto mais heterogêneo for esse público, mais diversificado deverá ser o acervo como é o caso da biblioteca pública. $\mathrm{O}$ usuário poderá ser o adulto que se alfabetiza ou o geneticista que tem interesse profissional em acompanhar passo a passo os avanços científicos de seu setor (p. 14).

(....) A ciência é cumulativa e a biblioteca tem a função de preservar a memória - como se ela fosse o cérebro da humanidade - organizando a informação para que todo ser humano possa usufruí-la. Isso vai da biblioteca que se constrói para aqueles que se alfabetizam, até a biblioteca especializada para o homem de ciência (p. 15).

Contudo, as bibliotecas selecionadas e retratadas nos depoimentos dos pesquisadores apresentaram uma configuração bem diversa daquela forma ideal apontada por Milanesi (1983), ao se referir à biblioteca pública:

Com a intenção de pesquisar sobre as bibliotecas públicas da cidade do Rio de Janeiro, resolvemos visitar a Biblioteca Popular do Engenho Novo, que foi inaugurada em 1960, em um casarão de Rua Silva Rabelo, com o nome de Serafim da Silva Neto e o seu acervo era de 8.500 livros. Hoje, esta biblioteca tem o nome de Agripino Grieco e atende mais de 150 pessoas por dia, sendo a maior parte de estudantes, que moram no bairro do Méier, Engenho Novo, Lins, Riachuelo e Engenho de Dentro (FIGUEIREDO, MARTINS, CRISTINA e BRITO, 2005, p.1).

Funcionamento da biblioteca Popular da Penha - Álvaro Moreyra (...). Quanto aos leitores, averiguamos que a maioria mora na Penha, é jovem e estudante da rede pública, que procura a biblioteca para realizar tarefas e pesquisas escolares. Sobre o perfil desse leitor que freqüenta a biblioteca, é interessante notar que, quando questionados sobre o prazer de ler, sempre dizem que só fazem pesquisas, ou seja, que não estão interessados em ler um livro por pura curiosidade ou prazer (LOURENÇO, MONTEIRO e CRISTINA, 2005, p.5). 
Biblioteca Cruz e Souza (Bangu). O público é formado, em sua maioria, por estudantes do ensino fundamental das redes pública e privada da região. Sendo que, no final do ano (época de provas), o número de visitantes chega a 100 por dia e algumas escolas realizam visitas guiadas à biblioteca (DIAS, NOGUEIRA, DUARTE E MOREIRA, 2005, p.8)

Nos depoimentos transcritos acima aparecem algumas observações interessantes, quando confrontadas com as definições de natureza teórica: a presença de jovens leitores, em sua maioria estudante, interessados em desenvolver pesquisa estritamente escolar. Essas constatações se distanciam, de fato, das definições teóricas estudadas. Lembre-se que, para Milanesi (1983), "quanto mais heterogêneo o público, mais diversificado será o acervo - como é o caso da biblioteca pública”, além de funcionar como o espaço de organização do saber para que todo ser humano tenha acesso à informação.

Diante das noções construídas previamente, não é de se estranhar que os pesquisadores tenham ficado bastante impressionados com o perfil do leitor estudante, em razão do restrito interesse em pesquisa e tarefas escolares; o que revela, entre outros determinantes, a indispensável articulação entre teoria e prática no processo de produção do conhecimento.

Compreendemos, portanto, a necessidade de contrapor às leituras teóricas os dados da pesquisa de campo. Como fazê-lo, com um grupo numeroso, recém chegado à Universidade, começando o exercício da pesquisa?

Optamos por uma metodologia que levasse em consideração, de um lado, o aprofundamento dos textos teóricos que tratam de bibliotecas populares/ públicas e de suas funções, como pode ser observado em Silva (2004), Milanesi (1983) Lindoso (2004); de outro, percebemos a urgência de refinar o olhar em direção à coleta de dados e de sensibilizá-lo. É interessante perceber o que se diz e o que se cala; aquilo que nos parece 
evidente em confronto com o que é revelado. Esse exercício tornou-se possível, a princípio, por meio da leitura de textos literários que indicam a observação acurada em relação ao real e a capacidade de falar à imaginação.

Observe-se um texto literário que nos fez refletir sobre o movimento do real e a acuidade necessária no que diz respeito ao olhar do pesquisador:

\begin{abstract}
Palomar na praia
Leitura de uma onda

O mar está levemente encrespado e pequenas ondas quebram na paria arenosa. O senhor Palomar está de pé na areia e observa uma onda. Não que esteja absorto na contemplação das ondas. Não está absorto, porque sabe bem o que faz: quer observar uma onda e a observa (...). Em suma, não são as ondas que ele pretende observar, mas uma simples onda e pronto: no intuito de evitar as sensações vagas, ele predetermina para cada um de seus atos um objetivo limitado e preciso. O senhor Palomar vê uma onda apontar na distância, crescer, aproximar-se, mudar de forma e de cor, revolver-se sobre si mesma, quebrar-se, desfazer-se. A essa altura poderia convencer-se de ter levado a cabo a operação a que se havia proposto e ir-se embora. Contudo, isolar uma onda da que lhe segue de imediato e que parece às vezes suplantá-la ou acrescentar-se a ela e mesmo arrastá-la é algo muito difícil (,...).Em suma, não se pode observar uma onda sem se levar em conta os aspectos complexos que concorrem para formá-la e aqueles a que essa dá ensejo (CALVINO, 1994, p. $7-8)$.
\end{abstract}

O fragmento destacado, em que Ítalo Calvino constrói um personagem contemplando a natureza - o movimento de uma onda - com pretensões de descrevê-la, abarcá-la em suas múltiplas dimensões, é um bom exemplo do que tem sido o nosso exercício, com vistas a introduzir noções concernentes à realização da pesquisa em um curso de graduação. Leitura de uma onda, em particular, permitiu discussões instigantes sobre a percepção da produção de conhecimento em seu caráter histórico, dialético, repleto de contradições.

Assim, perceber a dinâmica de funcionamento das bibliotecas populares, no horizonte desta pesquisa, implica olhar além das aparências, 
dos objetivos previamente traçados, dos dados estatísticos sobre leitura e leitores divulgados pelos órgãos governamentais. Significa assumir o campo de investigação como "o mar encrespado" que tanto assusta o personagem Palomar. Indica, além disso, uma disposição de observar as bibliotecas tal como uma onda em movimento, sem ser possível isolar um fato, descrevêlo, desconsiderando o seu relacionamento com o movimento de outros aspectos que compõem essa totalidade.

Compreendemos, então, uma condição para o desenvolvimento da pesquisa: não perder de vista os pequenos indícios assim como a percepção global da realidade.

Outro relato dos pesquisadores pode ilustrar esse entendimento:

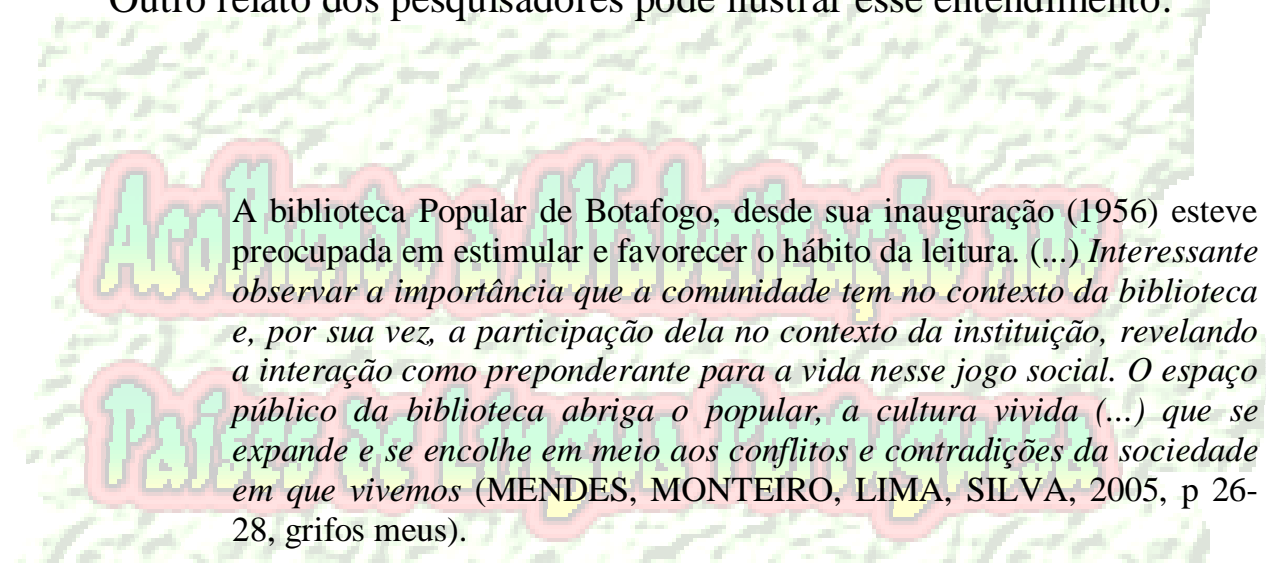

A biblioteca Popular de Botafogo, desde sua inauguração (1956) esteve preocupada em estimular e favorecer o hábito da leitura. (...) Interessante observar a importância que a comunidade tem no contexto da biblioteca $e$, por sua vez, a participação dela no contexto da instituição, revelando a interação como preponderante para a vida nesse jogo social. $O$ espaço público da biblioteca abriga o popular, a cultura vivida (...) que se expande e se encolhe em meio aos conflitos e contradiçóes da sociedade 28 , grifos meus).

Ao lado de estudos teóricos sobre a construção do método, propondo o sujeito como ordenador e construtor da experiência (OLIVEIRA,1998 e PÁDUA, 2004), utilizamos a estratégia da contemplação de filmes, que exercitassem o olhar crítico e sensível do pesquisador e a compreensão do estudo para além do campo de investigação restrita. Pesquisar o acesso à leitura, nesta perspectiva, coloca em jogo o campo da cultura, da história, assim como as políticas públicas e sociais.

O filme Narradores de Javé bem ilustra essa percepção: 


\begin{abstract}
O filme conta a história de um povoado fictício (Javé), prestes a ser inundado, devido à construção de uma hidroelétrica. Para evitar a catástrofe, os habitantes resolvem escrever sua história e, possivelmente, transformar a cidade em um patrimônio histórico a ser preservado. $\mathrm{O}$ único adulto alfabetizado do local é escolhido para colher as histórias sobre Javé e registrá-las em papel, elevando-as ao estatuto de cientificidade. Biá é um floreador de história, com uma incrível capacidade de aumentá-la e modificá-la, do mesmo modo que os diversos narradores escolhidos para contá-las. Em meio à tentativa de registro das múltiplas versões, é curioso que Biá, ao final, entregue um livro em branco para a população. Podemos ler esse gesto como a impossibilidade de registrar a variedade de todos os discursos sociais em jogo. Mais curioso ainda é o seu gesto final: segue caminhando de costas, observando o passado ser destruído pelo progresso, pela novidade que pode representar a hidroelétrica. Um último gesto de resistência, talvez (SILVA, 2004b).
\end{abstract}

A história poderia, evidentemente, suscitar outras interpretações por parte do espectador: a transformação do sertão em mar afogaria irremediavelmente a memória, a cultura e a história dos antepassados ou, ao contrário, assim como os personagens foram capazes de criar diferentes versões sobre a história de Javé, a história mostra que a memória pode ser inscrita nos monumentos, na lembrança dos que sobreviveram às catástrofes; além de muitas outras versões, conforme a imaginação dos múltiplos espectadores sociais.

O debate sobre o filme, acrescido da elaboração de resenhas, possibilitou, em especial, a reflexão sobre o conceito de leitura. Verificamos a necessidade de o leitor dialogar com os elementos da obra, com a intenção do autor, uma vez que leitura pressupõe sempre atitude ativa por parte de quem lê, ao selecionar os elementos do texto e propor-lhes novos significados. Delineado dessa forma, o conceito de leitura permitiu-nos romper com a idéia monolítica e homogênea que se tem comumente de seu processo, dado como natural. A fim de subsidiar a sistematização do conceito, leituras teóricas foram também de grande valia, em especial, os estudos de Freire (1998), Martins (1996), Silva (2004), Zilberman E Silva (1991). 
A concepção de história, como possibilidade de mudança dos fatos acontecidos e em uma perspectiva de recontá-los de modo singular, consistiu em outra contribuição importante derivada do diálogo com o filme linhas acima referido. Nesta perspectiva, selecionamos para leitura dois estudos antológicos do filósofo Walter Benjamin: O Narrador e Sobre o Conceito de História (BENJAMIN, 1987). No primeiro, dentre os diversos temas abordados, sublinhamos a preocupação com a perda da experiência no homem moderno. Da análise do segundo, extraímos, em especial, uma compreensão crítica em relação à concepção evolucionista da história. Presente, passado e futuro precisam ser pensados, segundo as originais teses do filósofo, como campos entrecruzados.

Além disso, para investigarmos o histórico das bibliotecas populares, recuperamos parte significativa dos estudos relativos à história da leitura, em uma perspectiva teórica e metodológica própria da História Cultural. Com efeito, a categoria de análise apropriação, proposta por Roger Chartier (1990, 1996), em suas pesquisas sobre a história do leitor, da leitura e de seus suportes, tem orientado a forma como nos aproximamos das fontes históricas relativas às bibliotecas públicas.

Conforme a história da leitura ensina, ao mudarem-se os suportes onde se registram os textos, transformam-se consideravelmente as relações e as formas de apropriação entre o leitor e o material impresso. (SILVA, 2004a).

De tal modo, o conceito de práticas de leitura, mesmo tendo-se em conta um dado período de tempo e um determinado espaço, como é o caso do recorte desta pesquisa ${ }^{3}$, não se limita a um corpo homogêneo.

Chartier acrescenta considerações interessantes a este respeito:

\footnotetext{
${ }^{3}$ A pesquisa em foco compreende três etapas: $1^{\mathrm{a}} \mathrm{o}$ histórico das bibliotecas populares e o modo de funcionamento atual; $2^{\mathrm{a}}$ modos e gestos de leitura configurados nesses espaços e $3^{\mathrm{a}}$ a organização, a circulação e a recepção do acervo. O processo que envolverá as três fases está previsto para ser desenvolvido no período compreendido entre 2004 a 2007.
} 
(...) cada leitor, a partir de suas próprias referências, individuais ou sociais, históricas ou existenciais, dá um sentido mais ou menos singular, mais ou menos partilhado aos textos de que se apropria. Reencontrar esse fora-do-texto não é tarefa fácil, pois são raras as confidências dos leitores comuns sobre suas leituras (CHARTIER, 1996, p.20).

\section{A dinâmica das bibliotecas populares}

No que diz respeito aos instrumentos da pesquisa, tendo em vista que nossa intenção inicial foi apreender a história das bibliotecas populares, o caderno de campo constituiu-se um dispositivo fundamental para o registro das fontes. Foi possível, por exemplo, registrar dados extraídos de documentos oficiais - atos governamentais, decretos - recortes de jornal, contendo discursos por ocasião da inauguração das bibliotecas; depoimentos de pessoas que, de algum modo, estiveram ou estão ligadas à história das bibliotecas públicas. A seguir, destacamos alguns dados relevantes extraídos dos diversos documentos consultados ${ }^{4}$, com o intuito de mapear elementos relativos ao histórico e ao modo de funcionamento atual das bibliotecas pesquisadas:

Biblioteca Popular de Bangu - Cruz e Souza. Inaugurada em 18 de dezembro de 1981, atende a leitores residentes nos bairros de Bangu, Santíssimo, Realengo, Valqueire, Senador Câmara, Padre Miguel e Deodoro. Por dia passam pela biblioteca cerca de cem pessoas. Destacamse as seguintes atividades: Gibiteca, brinquedoteca, hora do conto e oficinas.

\footnotetext{
4 Distrito Federal, Resolução no 2, de 05 de janeiro de 1945. Instala vinte bibliotecas populares no Distrito Federal. Distrito Federal, Decreto n ${ }^{\circ} 13.455$, de 31 de janeiro de 1957. Aprova o regulamento das bibliotecas populares da Secretaria Geral de Educação e Cultura. Estado da Guanabara. Decreto 1594, de 25 de março de 1963. Organiza a Secretaria de Educação e Cultura. Rio de Janeiro, Decreto no 15, de 23 de maio de 1975. Dispõe sobre a estrutura orgânica da Secretaria Municipal de Educação e Cultura e estabelece sua competência. Rio de Janeiro, Lei n ${ }^{\circ}$ 1598, de 30 de agosto de 1990. Autoriza o poder executivo a dar nomes de autores da Literatura Brasileira às Bibliotecas Populares mantidas pelo Município. Rio de Janeiro, Decreto n ${ }^{\circ}$ 10.205, de 18 de junho de 1991. Dispõe sobre a denominação das Bibliotecas Públicas Municipais.
} 
Biblioteca Popular de Botafogo - Machado de Assis. Inaugurada em 20 de janeiro de 1956. Está instalada num prédio neoclássico de 1929 , construído pela família Castro Maya para residência. Além de Botafogo, atende os bairros adjacentes, como Flamengo, Largo do Machado, Laranjeiras e Cosme Velho. Cerca de 150 pessoas passam diariamente pela biblioteca. As principais atividades São: Encontros para a terceira idade, encontro de poetas, cursos e oficinas, pólo de jornal em biblioteca.

Biblioteca Popular do Engenho Novo - Agripino Grieco. Inaugurada em 22 de novembro de 1960, em um casarão da Rua Silva Rabelo, com o nome de Serafim da Silva Neto e o acervo inicial de 8.500 livros. Atende cerca de 150 pessoas por dia, na maioria estudantes residentes nos bairros do Méier, Engenho Novo, Lins, Riachuelo e Engenho de Dentro. Destacam-se as seguintes atividades: gibiteca, brinquedoteca, bibliocine e hora do conto.

Biblioteca Popular do Grajaú - Clarice Lispector. Inaugurada em 26 de fevereiro de 1974, foi criada por sugestão do professor Diofrildo Trotta, diretor da Escola Municipal Francisco Campos, Como acervo inicial, recebeu os livros que pertenciam à biblioteca da escola. Atende cerca de 50 pessoas por dia, a maioria estudantes de Grajaú, Vila Isabel e Andaraí. Principais atividades: brinquedoteca, bibliocine e hora do conto.

Biblioteca popular de Irajá - João do Rio. Inaugurada em 16 de julho de 1959. Primeira biblioteca da rede a funcionar em prédio construído para essa finalidade, para o qual foi transferido em 18 de dezembro de 1992. Atende por dia cerca de cem leitores, na maioria estudantes, oriundos de Irajá e bairros adjacentes e também de Nilópolis. Destacam-se as seguintes atividades: gibiteca, brinquedoteca, oficinas para a terceira idade, games, videoteca, muitimídia, acesso à internet e pólo de jornal em biblioteca.

Biblioteca Popular da Penha - Álvaro Moreyra. Inaugurada em 16 de novembro de 1978. Foi a segunda biblioteca popular a desenvolver a seção braille e a única designada por cordelteca, com pesquisa e concursos de literatura de cordel. Atende cerca de cem pessoas por dia, na maioria estudantes, provenientes de todos os bairros da Leopoldina e de municípios vizinhos. Atividades: gibiteca, brinquedoteca, cordelteca, palestras, oficinas, exposições e pólo de jornal em biblioteca.

Biblioteca Popular de Santa Teresa - José de Alencar. Inaugurada em 15 de outubro de 1971. Desde 6 de junho de 1996, está no anexo do Centro Cultural Laurinda Santos Lobo. Atende aproximadamente, 60 leitores por dia, na maioria estudantes de Santa Teresa, Centro e catumbi. Atividades: Gibiteca, brinquedoteca, hora do conto, oficinas e cursos, palestras e acesso à internet.

Biblioteca Popular da Tijuca - Marques Rebelo. Inaugurada em 29 de setembro de 1960. Está no atual endereço desde 12 de março de 1979 (Rua Guapeni, 61).Atende cerca de cem leitores diariamente, grande parte 
deles pessoas que trabalham na Tijuca e moram em outros bairros. Atividades: Pólo de jornal em biblioteca, cursos e encontros com a terceira idade.

As bibliotecas focalizadas foram inauguradas ao longo das décadas de 1950, 1960, 1970 e início da década de 1980. Período histórico bastante restritivo em relação ao acesso de bens culturais, visto que, como se sabe, o país atravessava regime autoritário dos mais violentos de nossa história. Pudemos observar que as atividades, em sua maioria, têm sido organizadas em torno do que designam por brinquedoteca (em grande parte consiste em coleções de jogos didáticos), da gibiteca e da hora do conto. As condições históricas por ocasião de sua implementação devem ter sido determinantes para o desenvolvimento de atividades prioritariamente lúdicas. Os eventos de caráter mais reflexivo e analítico, como palestras e cursos, embora constem da programação, mostraram-se efetivamente rarefeitos.

Por outro lado, chamou bastante a atenção o fato de só $50 \%$ das bibliotecas pesquisadas disporem de jornais diários para consulta, conforme pode ser percebido por meio da observação da atividade designada por pólo de jornal em biblioteca. Como ter acesso à informação, minimamente, sem a possibilidade de consultar jornais diários ou outros meios de informação equivalentes, tais como periódicos que abordem os fatos recentes acontecidos no mundo contemporâneo?

Além disso, as hipóteses quanto ao perfil do leitor levantadas pelos pesquisadores por ocasião das primeiras visitas realizadas puderam ser confirmadas. Considerando-se a freqüência diária nas oito bibliotecas pesquisadas, variando entre 50 a 150 pessoas, a grande maioria constitui-se estudantes do ensino fundamental e médio.

Cuidamos, portanto, de perceber que os dados recortados e selecionados têm relevância, e nossa tarefa não é neutra.

No estudo de metodologia em Ciências Humanas, é preciso optar a respeito daquilo que precisa ser registrado, o que pode ficar de fora. Como 
afirma Chauí, discutindo a ilusão da neutralidade da ciência: "Quando o cientista escolhe uma certa definição de seu objeto, decide usar um determinado método e espera obter certos resultados, sua atividade não é neutra nem imparcial, mas feita por escolhas precisas (CHAUÍ, 1994. p. 281).

Em se tratando de pesquisa no âmbito das Ciências Humanas, lembramos que há outro cuidado a ser tomado; neste caso, a pesquisa envolve o homem, que se torna, ao mesmo tempo, sujeito e objeto da investigação científica (cf. OLIVEIRA, 1998 e PÁDUA, 2004).

Esse cuidado aparece evidenciado em muitos dos relatórios de final de curso, desenvolvidos pelos pesquisadores sobre a rede de bibliotecas populares da Cidade do Rio de Janeiro e a formação de leitores. Destacamos um dos depoimentos que ilustra a atitude sublinhada acima:

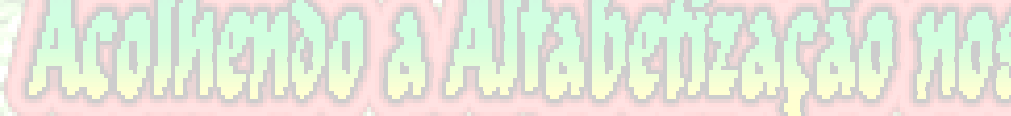 \\ Conhecer a biblioteca, além do aço das estantes, da fórmica das mesas, do silêncio, por vezes aterrador das salas, inseriu-nos num contexto de maturidade científica, por demais significativo e estimulante. Tivemos o privilégio de conhecer, confrontar e dialogar com as pessoas que, diferentemente de "atuarem no balcão", repetindo o desconforto de quem é retirado da paz e segurança da pacata instituição pública, receberam-nos com carinho e dedicação; palavras bem subjetivas para explicitar a admiração pelo trabalho de domingo a domingo, mas não ocorrem outras melhores para expressar os nossos sinceros agradecimentos pela acolhida, recepção e disposição para esclarecer nossas dúvidas (tantas dúvidas). A Biblioteca Machado de Assis reserva um pouco do mundo, faz parte do mundo e possui as alegrias, contradições e incertezas de nosso tempo (MENDES, MONTEIRO, LIMA, SILVA, 2005, p. 35-36, grifos meus).}

\section{Considerações finais acerca das bibliotecas pesquisadas}

A reunião de um conjunto de dados relevantes sugere caminhos para uma sistematização inicial: a) Conforme os índices coletados, desde a década de 1950 até o início da década de 80, as bibliotecas populares da Cidade do Rio de Janeiro selecionadas para esta pesquisa foram 
implementadas. Não obstante o momento histórico comum, cada biblioteca foi constituída com marcas de singularidade e segue um movimento próprio. Assim, procuramos relacionar o momento histórico e os dados mais relevantes, de forma a não apagar os movimentos singulares de cada espaço investigado; b) Muitas dessas bibliotecas parecem funcionar como anexos de escolas públicas, evidenciando-se a presença constante de jovens estudantes do ensino fundamental e médio da rede pública de ensino, como o evidenciado nas seguintes instituições: Biblioteca Popular do Engenho Novo, Biblioteca Popular do Grajaú, Biblioteca Popular de Irajá, Biblioteca Popular da Penha, Biblioteca Popular de Santa Teresa. Estima-se, portanto, haver precariedade no que diz respeito ao acervo das bibliotecas das escolas públicas no contexto da Cidade do Rio de Janeiro, especialmente no que se refere a obras de referência e de textos científicos os quais costumam subsidiar pesquisa escolar. A articulação deste resultado com dados extraídos da investigação nas bibliotecas escolares e salas de leitura em funcionamento nas escolas públicas da Cidade do Rio de Janeiro pode indicar campo bastante favorável para pesquisas futuras; c) Em alguns momentos da história, baixaram-se decretos os quais designavam as bibliotecas com nomes de escritores ilustres, como pode ser observado nos exemplos a seguir: Biblioteca Popular da Penha - Biblioteca Álvaro Moreira; Biblioteca Popular de Santa Teresa - Biblioteca José de Alencar; Biblioteca Popular do Grajaú - Biblioteca Clarice Lispector ${ }^{5}$. Contudo, em conversa informal, os freqüentadores e funcionários costumam identificá-las apenas pelo nome do bairro em que estão localizadas. Esta evidência indica, sobretudo, que os decretos podem se anular, quando em confronto com a memória da comunidade; d) As bibliotecas populares registram atividades

\footnotetext{
${ }^{5}$ A este respeito, foram consultados dois documentos esclarecedores: Rio de Janeiro, Lei ${ }^{\circ}$ 1598, de 30 de agosto de 1990. Autoriza o poder executivo a dar nomes de autores da Literatura Brasileira às Bibliotecas Populares mantidas pelo Município do Rio de Janeiro e Rio de Janeiro, Decreto ${ }^{\circ} 10.205$, de 18 de junho de 1991. Dispõe sobre a denominação das Bibliotecas Públicas Municipais.
} 
consideradas culturais: hora do conto, oficinas, exibição de filmes, palestras para a terceira idade, dentre outras. Restaria investigar em fases posteriores se, de fato, as atividades em destaque, dialogam com a cultura local.

Por último, convém sublinhar o desenvolvimento da pesquisa, cujo tema refere-se a políticas públicas e formação de leitores, em um curso de graduação desde os períodos iniciais, o que, além de favorecer consideravelmente o exercício coletivo da produção de conhecimento, pôde permitir o trânsito dos alunos entre o ensino e a pesquisa, uma das funções primordiais da educação superior.

\section{Referências bibliográficas}

BENJAMIN, Walter (1987). Obras escolhidas: magia e técnica, arte e política. São Paulo: Brasiliense.

BRASIL, Instituto Brasileiro de Geografia e Estatística. Censo Demográfico 2000. Disponível em www.ibge.gov.br. Acesso em $\frac{\text { de }}{10 \text { de }}$ junho de 2005.

BRASIL, Instituto Brasileiro de Geografia e Estatística. Pesquisa nacional por amostra de domicílios, PNAD, 2002. Disponível em www.ibge.gov.br. Acesso em 10 de junho de 2005.

CALVINO, Ítalo (1994). Palomar. São Paulo: Companhia das Letras.

CBL/BRACELPA/SNEL/ABRELIVROS. Retrato da leitura no Brasil. Cd-rom. São Paulo: Franceschini, 2001.

CHARTIER, Roger (1990). A história cultural: entre práticas e representações. Lisboa: Difel; Rio de Janeiro: Bertrand Brasil. (1996). Práticas da leitura. São Paulo: Estação Liberdade.

CHAUÍ, Marilena (1998). Convite à filosofia. São Paulo: Ática. 
DISTRITO FEDERAL, Resolução no 2, de 05 de janeiro de 1945.

DISTRITO FEDERAL, Decreto n⿳ 13. 455, de 31 de janeiro de 1957

ESTADO DA GUANABARA. Decreto 1594, de 25 de março de 1963.

FERREIRA, Marieta de Moraes e AMADO, Janaína. (2002). Usos e abusos da história oral. Rio de Janeiro: Editora FGV.

FREIRE, Paulo (1998). A importância do ato de ler: em três artigos que se completam. São Paulo: Cortez.

LINDOSO, Felipe (2004). O Brasil pode ser um país de leitores? Política para a cultura/ política para o livro. São Paulo: Summus.

MARTINS, Maria Helena. (1996). O que é leitura? São Paulo: Brasiliense.

MILANESI, Luís (1983) O que é biblioteca. São Paulo: Brasiliense.

MINAYO, Maria Cecília de Souza. (1992). O desafio do conhecimento: pesquisa qualitativa em saúde. Rio de Janeiro, São Paulo: ABRASCO, HUCITEC.

MINAYO, Maria Cecília de Souza (org.) (1994). Pesquisa social: teoria, método e criatividade. Petrópolis: Vozes.

OLIVEIRA, Paulo de Salles (1998) Caminhos de construção da pesquisa em ciências humanas. In: OLIVEIRA, Paulo de Salles (org.). Metodologia das ciências humanas. São Paulo: Hucitec/Unesp.

PÁDUA, Elisabete Matallo Marchesini de. (2004) Metodologia da pesquisa: abordagem teórico-prática. Campinas; São Paulo.

QUALIDADE DA EDUCAÇÃO: uma nova leitura do desempenho dos estudantes da quarta série do Ensino Fundamental. INEP/MEC. Disponível em http://www.inep.gov.br. Acesso em 22 de abril de 2005. 
RIBEIRO, Vera Mazagão. (org.) (2003). Letramento no Brasil: reflexões a partir do INAF 2001. São Paulo: Global.

RIO DE JANEIRO. Decreto n⿳ 15, de 23 de maio de 1975.

RIO DE JANEIRO, Lei no 1598, de 30 de agosto de 1990.

RIO DE JANEIRO, Decreto n⿳ $\mathbf{1 0 . 2 0 5}$, de 18 de junho de 1991.

RIO DE JANEIRO. Secretaria Municipal de Culturas. Prefeitura do Rio - biblioteca - Era uma Vez. Rio de Janeiro: Departamento Geral de Documentação e Informação, s/d.

SILVA, Márcia Cabral da (2004a). Modos de leitura no catálogo da livraria José Olympio editora, de 1949. In: Leitura: Teoria e Prática. Ano 22, $\mathrm{n}^{\circ}$ 43, set. 2004 - Campinas, São Paulo: ALB; São Paulo: Global, 2004a.

SILVA, Márcia Cabral da (2004b). Sinopse sobre o filme Narradores de Javé, dirigido por Eliane Caffé, 2004, Brasil. Rio de Janeiro, 2004b (mimeografado).

SILVA, Márcia Cabral da et al.(2005). Relatório parcial da pesquisa sobre bibliotecas populares da Cidade do Rio de Janeiro e a formação de leitores. Rio de Janeiro. (mimeografado).

SILVA, Ezequiel Theodoro da. (2004) Leitura na escola e na biblioteca. Campinas-SP: Papirus.

ZILBERMAN, Regina e SILVA, Ezequiel Theodoro da. Leitura: perspectivas interdisciplinares. São Paulo: Ática. 


\section{Autora}

\section{Márcia Cabral da Silva}

Professora Adjunta da Faculdade de Educação, Universidade do Estado do Rio de Janeiro

E-mail: marciacs@ism.com.br

\section{Como citar este artigo:}

SILVA, Márcia Cabral da. Introdução à pesquisa em um curso de graduação: sobre bibliotecas populares e formação de leitores. Revista ACOALFAplp: Acolhendo a Alfabetização nos Países de Língua portuguesa, São Paulo, ano 2, n. 3, 2007. Disponível em: <http://www.mocambras.org> e ou <http://www.acoalfaplp.org>. Publicado em: setembro 2007. 